\title{
Clines, Clusters, and Clades in the Race Debate
}

\author{
Matthew Kopec*广
}

In this paper, I argue against Andreasen and Sesardic, who have both claimed that recent cluster results in population genetics serve as evidence that the human species contains, or at least once contained, subspecies. I show that the cluster results are in fact evidentially inert relative to each author's preferred subspecies concept. I then sketch the kinds of biological facts that could be used to push the debate further.

1. Introduction. The debate over the biological legitimacy of the human races seemed to be settled as little as 10 years ago, with the consensus being that human races are not biologically legitimate. This view was mainly based on two biological facts. First, the human population exhibits clinal variation, that is, human genetic and phenotypic characteristics vary gradually with distance, and there are no distinct boundaries between human populations (Livingstone 1962). Second, there is more genetic variation within the folk races than there is between them (Lewontin 1972). These biological facts have been taken by scholars across the humanities and social sciences to establish that human races lack any biological legitimacy.

Although no respectable scholars deny these facts, the biological legitimacy of the human races is once again under dispute (e.g., Andreasen 2007; Sesardic 2010; Hardimon 2012). Those who have recently argued for the bi-

*To contact the author, please write to: Department of Philosophy, University of Colorado-
Boulder, UCB 232, Boulder, CO 80309; e-mail: matthewckopec@gmail.com.
$\dagger$ I'd like to thank Dominic Bailey, Matthew Barker, John Basl, Daniel Hausman, Jonathan
Kaplan, Larry Shapiro, Elliott Sober, Quayshawn Spencer, and Rasmus Winther for their com-
ments on earlier drafts of this essay, as well as Alan Templeton and the audiences at CU-Boulder,
Northeastern University, University of British Columbia, UW-Madison, the International So-
ciety for the History, Philosophy, and Social Studies of Biology 2011, and PSA 2012 for help-
ful discussion. This research was funded under a project at Northeastern University's Ethics
Institute entitled Nanotechnology in the Public Interest: Regulatory Challenges, Capacity, and
Policy Recommendations (National Science Foundation, grant SES-0609078).

Philosophy of Science, 81 (December 2014) pp. 1053-1065. 0031-8248/2014/8105-0028\$10.00 Copyright 2014 by the Philosophy of Science Association. All rights reserved. 
ological legitimacy of the human races have turned to biological data of their own. New statistical procedures and advances in computing power have allowed population geneticists to examine human population structure in ways that were not available to Livingstone and Lewontin. What these new methods suggest is that some human populations do in fact cluster together on the basis of cross-locus genetic similarity and that these continental population clusters seem to approximate some standard folk racial categories (Pritchard, Stephens, and Donnelly 2000; Risch et al. 2002; Rosenberg et al. 2002; Bamshad et al. 2003; Li et al. 2008). The ability to find genetic population clusters that approximate the folk races suggests to many that the human races must be biologically legitimate after all.

In this paper I argue that this capacity to find continental population clusters ought not shake our confidence in the biological illegitimacy of human races. In section 2 I lay out four predominant race concepts biologists currently employ, namely, the variationist, ecological, populationist, and cladistic race concepts, and I show that the cluster results are clearly irrelevant to the first two concepts. In section 3 I show, contra Sesardic (2010), that using the population cluster results to affirm the existence of populationist human races conflicts with standard biological practice. In section 4 I show, contra Andreasen (2007), that the cluster results do not serve as evidence that cladistic human races once existed. In section 5 I sketch some biological data that would help us determine whether distinct human lineages existed in the past, which is a requirement for both Sesardic's and Andreasen's preferred subspecies concepts. I conclude in section 6 .

2. The Varieties of Biological Subspecies. The question "Are races biologically legitimate?" is multiply ambiguous, which has been the root of much confusion in the literature. Here are some of the possible interpretations. First, one might be asking whether there are any biologically relevant differences between the folk races. Second, one might be asking whether the folk races count as legitimate taxonomic units, that is, whether biologists should count the folk races as subspecies. Third, one might be asking whether the human species admits of any legitimate taxonomic subdivision, leaving open the further question about whether the resulting subspecies correlate with the folk races. And there are other possible interpretations; ${ }^{1}$ thus, it is important to be clear about which question we wish to examine.

Unfortunately, authors who use the population cluster results to reaffirm the biological legitimacy of the human races are typically silent about which particular question they are attempting to answer. Although all of these in-

1. For example, one might be asking whether the very concept of 'race' is something that can be legitimately employed in biology (see Spencer 2012). This interpretation of the question is the target of what Spencer (2013) calls the 'philosophical race debate'. 
terpretations could form the locus of an interesting debate, I am here concerned solely with the third interpretation. Therefore, I will hereafter take those who present the population cluster results as evidence that races are biologically legitimate as claiming that these new capacities provide evidence that the human species can be split into subspecies. I believe that this is at least part of what Sesardic (2010) and Andreasen (2007) intend their arguments to establish. ${ }^{2}$

To determine whether the population cluster results do in fact support the claim that humans admit of subspecies division, we need to be clear about which subspecies concept we are dealing with. There are four main subspecies concepts widely employed in biological taxonomy. First, what I call variationist subspecies are geographically circumscribed groups within a species that have a high level of within-group genetic similarity and a low level of between-group similarity. ${ }^{3}$ Second, ecological subspecies are local populations within a species that are adapted in important ways to their particular environment. ${ }^{4}$ Third, populationist subspecies are groups within a species that exhibit some noticeable cross-locus genetic differences due to partial genetic isolation. ${ }^{5}$ Fourth, cladistic subspecies are relatively large groups within a species that form distinct lineages, or, in other words, there have been only a small number of reproductive events that have taken place between these large groups over an extended period of time. ${ }^{6}$

2. Sesardic (2010) may well have the second interpretation in mind, but the third must be settled before the second can be, thus making the third a better starting point.

3. The label 'geographical' subspecies is the one typically used for these kinds of groups (Templeton 1998), but I expect that such a label would cause confusion in the current context, since the cluster results might seem to trivially support the existence of such groups. They are geographically located groupings, after all. They are also sometimes referred to as 'taxonomic' subspecies when the focus is on phenotypic as opposed to genetic characteristics (Long and Kittles 2003).

4. They are also known as 'ecotypes'. Though the concept of an ecological subspecies was only occasionally employed when it first came to the race literature via Pigliucci and Kaplan (2003), its use is quickly becoming commonplace in the biological literature. For example, a Google Scholar search for the term 'ecotype' returned over 70,000 results as of June 2013.

5. This is essentially the race concept employed by Sesardic (2010) and is closely related to the concept presented by Hardimon (2012), although the latter focuses on phenotypic variation to keep a closer tie with folk concepts of race (cf. Hardimon 2003). The concept is often traced back to Dobzhansky (1970). My use is slightly different from that of Glasgow (2009, 91-108), since Glasgow lumps Andreasen in as a populationist. She will not qualify on my account, since she does not claim that genetic clustering is a necessary condition for subspecies division. As a cladist, genetic differentiation will serve merely an epistemic purpose.

6. Some authors (e.g., Andreasen 2007) also discuss typological or essentialist subspecies, but essentialist taxonomy has largely been purged from contemporary biology, 
Of these four subspecies concepts, the population cluster results could only be relevant to the latter two. To explain why, here is a quick sketch of how the population cluster studies work, focusing on the most influential of these studies, Rosenberg et al. (2002). In this study, the authors fed the genotypes of 1,052 individuals from 52 populations into STRUCTURE, a statistical program that examines cross-locus genetic similarity to determine population structure. As they state, "We identified six main genetic clusters, five of which correspond to major geographic regions" (2381). Since these major geographic regions also correspond well with some folk racial categories, these results have been taken to support the biological reality of human races.

Now I will explain why the cluster results cannot serve as evidence for either variationist or ecological subspecies, starting with the former. Recall that variationist (or "geographical") subspecies are geographically circumscribed groups within a species that have a high level of within-group similarity and a low level of between-group similarity. The way subspecies division of this sort is determined is by looking for geographically circumscribed groups that meet a certain threshold of genetic differentiation, typically measured by Sewell Wright's $F_{\mathrm{st}}$ statistic (Templeton 1998). Ever since Lewontin (1972), biologists have recognized that human populations do not meet the standard threshold needed for subspecies division of this sort. Or, in other words, marking off subspecies in the human population at such low levels of genetic differentiation would be to make a biological exception for humans. As Templeton has noted (1998, 633-35), there are many species exhibiting much higher levels of genetic differentiation than we see in humans, even though biologists do not believe that these species admit of subspecies division. Rosenberg et al.'s results do not dispute any of thisin fact, they note that "within-population differences among individuals account for 93 to $95 \%$ of genetic variation" (2381), which actually helps to make Templeton's point. Clustering programs like STRUCTURE do not show that there is more variation between (rather than within) human populations than we had originally thought. The programs simply tap into correlations found in the small amount of between-population variation that we already knew existed. Thus, the cluster results do not serve as evidence for variationist subspecies.

Third, recall that ecological subspecies (or "ecotypes") are local populations adapted in important ways to their particular environments. Although the environments on different continents certainly differ, with different populations adapting to their environments in different ways, the existence of

and with good reason (see Sober 1980; Wilson, Baker, and Brigandt 2007). Thus, this concept can be ignored without much loss. 
genetic population clusters does not really tell us anything about the distinctness of the niches inhabited by the respective populations or how these populations have adapted to them. And, as Pigliucci and Kaplan have noted, "Similar ecotypic characteristics can and do evolve independently in geographically separated populations. . . These similar phenotypic characteristics may, or may not, be mediated by similar genetic differences from other populations of the species. . . Further, a single population can consist of multiple overlapping ecotypes" (2003, 1163-64). This gap between niches, genes, and geography suggests that we cannot determine whether two groups are distinct ecotypes merely by looking at the genetic and geographical facts. ${ }^{7}$ Thus, the population clusters reported by Rosenberg et al. cannot be used to establish the existence of human ecological subspecies.

Are the population cluster results relevant to the two subspecies concepts that remain, namely, the populationist and cladistic concepts? I turn to these in the next two sections, respectively.

3. Are Population Clusters Evidence for Populationist Races? Sesardic (2010) defends the biological legitimacy of the human races on the basis of the cluster results in Rosenberg et al. (2002). Sesardic argues that race scholars in the humanities and social sciences often utilize overly restrictive race concepts in their attempts to delegitimize race. These scholars, he argues, often add essentialist criteria into the race concept they present-criteria we know no human populations can meet. Although one could dispute whether all of the race scholars he cites do in fact make such a presumption, ${ }^{8}$ there is no disputing that it would be a mistake to insist on essentialist criteria for the biological existence of human races. Essentialism of this sort has long been purged from biology (Sober 1980; Wilson et al. 2007), and there are a number of biological subspecies concepts that do not make such a requirement. In short, Sesardic's essay attempts to show that contemporary race scholars are out of touch with contemporary biology.

7. In fact, Kaplan (2011) mounts his own attack on those who attempt to use the population cluster results to support the existence of human races, and Winther and Kaplan (2013) have further argued that the population genetic data underdetermine whether ecological races exist.

8. For example, Sesardic lumps Andreasen, Kitcher, Pigliucci and Kaplan, and Appiah in with the other race scholars he believes utilize this straw-man strategy. This is odd. Andreasen is the central defender of human cladistic races (2007, 471-77), Kitcher at one point develops a new race concept that is based on differential rates of reproduction (1999, 239-42), and Pigliucci and Kaplan claim that human ecotype races "do in fact exist" $(2003,1161)$. None of these race concepts are guilty of the essentialism that concerns Sesardic. Lastly, Appiah writes, "I have no problem with people who want to use the word 'race' in population genetics" $(1996,471)$. Thus, his criticism of these scholars is misleading. 
Sesardic favors a subspecies concept akin to the populationist concept of Dobzhansky (1970). For Sesardic, "Subspecies are populations of organisms that, despite belonging to the same species, differ among themselves with respect to frequencies of alternative alleles at a number of loci. These differences are the result of these populations being at least partly isolated from one another long enough for a genetic differentiation to develop" (2010, 148). This definition seems to state two distinct conditions that are individually necessary and collectively sufficient for two groups to count as distinct subspecies. Sesardic goes on to claim that population cluster results like those presented in Rosenberg et al. (2002) and Risch et al. (2002) ought to shake our confidence in the biological illegitimacy of human races. Thus, Sesardic is arguing that the population cluster results are evidence that the clusters found in these studies count as populationist subspecies in the sense sketched above. I argue below that Sesardic is mistaken.

First, Sesardic, in his article, focuses solely on the first condition in his definition of a subspecies, namely, that the populations must differ with respect to gene frequencies at a number of loci. The population clusters found in these studies do in fact serve as evidence that the condition is met, since the clusters are determined based on the gene frequency differences at a number of loci. But Sesardic never provides an argument that the clusters presented in these studies serve as evidence that the differences between these populations are due to past isolation. This is problematic, since evidence that supports one condition need not support a conjunction of conditions. ${ }^{9}$ Of course, I will need some argument that the cluster results do not serve as evidence for the second condition, namely, that isolated populations existed in the past. I provide this argument in the next section while addressing the cladistic race concept, which is closely related to Sesardic's second condition.

It is worth taking a moment to determine whether Sesardic's second condition could be dropped without loss, because, if so, the cluster results would indeed serve as evidence for the existence of human subspecies in this weaker sense. Here I believe that it is useful to turn to scientific practice, a strategy Sesardic would need to allow given that his main criticism of contemporary race scholars is that their views run afoul of contemporary biology. Frantz et al. (2009) collected genetic samples from wild boar populations around Europe and fed the genetic information of these organisms into the statistical clustering program STRUCTURE and two successor programs

9. If it is not obvious why this is the case, here is an example. If my poker hand contains all spades, this is evidence that the conditions required for having a flush are met (namely, that all the cards are of the same suit), but it is not evidence that the conditions for having a club flush are met (namely, that all the cards are of the same suit and the cards happen to all be clubs). 
BAPS and GENELAND. The intention was to use these "Bayesian clustering methods to correlate genetic discontinuities with landscape features and thereby identify geographical barriers to gene flow that could be used to effectively delimit management units" (494). Although some of these programs found population clusters and some of the programs settled on roughly the same clusters, these biologists did not then take this information as evidence of new subspecies of wild boar. Instead, they insisted that one look for the geographic barriers that would hinder gene flow between the populations. They worried that "the program might overestimate genetic clustering of the data and not be capable of correctly detecting and locating a genuine genetic discontinuity" (494). Since no such barriers could be found in many cases, they concluded, "It was thus not possible to ascertain with confidence whether the clustering solutions offered by the various programs were an accurate reflection of population genetic structure in our empirical data set" (503). This suggests that the existence of genuine genetic discontinuity_or, in Sesardic's terminology, "isolation"-is needed for the resulting clusters to count as biologically interesting units. Thus, if the clusters are showing up because of mere deviations from random mating in the metapopulation, as opposed to actual breaks in gene flow, they should not be considered taxonomically distinct groups.

4. Are Population Clusters Evidence for Cladistic Races? In a series of articles, Andreasen has argued that human races are biologically legitimate because there are cladistic subspecies within the human species (1998, 2000, 2004, 2005, 2007). ${ }^{10}$ Recall that cladistic (or "phylogenetic") subspecies are relatively large groups within a species that form distinct lineages, or, in other words, there is a relatively low level of reproductive events between these large groups (Templeton 1998). Cladistic taxonomy consists in drawing a branching structure that represents genealogical relationships between groups of organisms that share genes only at very low rates. ${ }^{11}$ So, for example, if a subset of a population leaves for a new far-off continent, thus causing the founder population and the original population to stop reproducing with each other, then over time this subset would become a distinct taxonomic unit. Since cladists are merely concerned with reconstructing the so-called tree of life, issues of genetic variation or differentiation play an epistemic role in

10. This may be slightly misleading, since her considered view is that the human population used to exhibit cladistic subspecies but no longer does. I gloss over the distinction here for dialectical reasons.

11. Cladists would not want to insist that there be absolutely no gene exchange between taxonomic groups, since hybrid species are common in the biological world, and lateral gene transfer is proving to be much more common than originally thought. But even if some genes pass between the groups, the groups can still count as distinct taxonomic units so long as they closely approximate distinct lineages. 
taxonomy, as opposed to a constitutive role. In other words, genetic variation might be helpful when inferring which groups count as distinct phylogenetic units, but two groups could count as distinct phylogenetic units without there being much genetic variation at all. ${ }^{12}$

By utilizing this cladistic subspecies concept, Andreasen argues that our current evidence suggests that human subspecies are biologically legitimate. Andreasen appeals to work by various population geneticists who have argued that the human population likely fits a branching lineage structure. As she states, "A number of different research groups have proposed branching diagrams that aim to represent human evolutionary history-i.e., patterns of migration and subsequent geographic isolation among human breeding populations" $(2007,472)$. She concludes that if these diagrams are well supported, then we have some reason to accept that human subspecies do in fact exist. ${ }^{13}$

The problem is that there are many instances where one can represent a population using a branching diagram even though the population does not contain any truly isolated breeding populations. As Templeton puts it, "The computer programs used to generate 'trees' from genetic distance data will do so regardless of what evolutionary factors generated the distances" (1998, 639). After biologists go through the process of drawing trees based on the genetic distances between the populations, they must complete the further step of testing whether the populations do in fact fit a tree-like structure or "treeness." And, he points out, "the failure of human genetic distances to fit treeness is ubiquitous whenever tested. . . . Not one of the data sets fits treeness" (639). Templeton's argument thus casts doubt on the current existence of human cladistic subspecies.

Andreasen responds to arguments like Templeton's by pointing out that the human population may have admitted of distinct lineages at one point in time, but that these distinct lineages became reproductively linked once again through increased exploration and subsequent colonialization. As she puts it, "The data are consistent with the possibility that, while there may be significant outbreeding today, there was once enough reproductive isolation for distinct lineages to have evolved" $(2007,474) .{ }^{14}$ Thus, Andreasen ultimately argues for a rather unique position within the race debate. Her view is

12. A view that allows two almost genetically identical groups to count as distinct taxonomic units might seem to some as a nonstarter. Luckily, evolution will erase such a worry in real-world cases. Genetic variation is virtually guaranteed to arise if the lineages remain isolated for any sizeable period of time.

13. Or at least that they existed in the past. Again, I gloss over this distinction for the moment for dialectical reasons.

14. I should point out that the phrase 'reproductive isolation' is ambiguous, which has been the cause of much confusion. For Andreasen, 'reproductive isolation' means simply that reproductive events between the two populations are rare during some sizeable time 
that human races are biologically legitimate in the sense that there once were biologically legitimate human subspecies, but races as we currently understand them might well be merely socially constructed. ${ }^{15}$

While Andreasen's response here handles Templeton's objection, Gannett (2004) points out that biologists like Templeton have a deeper line of attack available. There are currently two dominant models of human evolutionary history. The first model holds that the human species split into distinct lineages and then those populations eventually began exchanging genes again. This is the model that Andreasen favors. The second model, which Templeton calls the 'trellis' model, holds that all major human populations have been exchanging genes throughout their history, and thus no distinct lineages ever existed. According to Templeton, the biological data support the latter view. He claims that when we look at the genetic distance data for the world's populations, we see that genetic differentiation increases with geographic distance. This suggests that the genetic differentiation we see is due to the fact that human populations typically reproduce with their close neighbors, causing genes to transfer more slowly along the range of the human species. This phenomenon, called 'isolation by distance', then serves as an explanation for the clinal nature of the human population. Genes vary gradually over distance because our ancestors were much more likely to mate with their neighbors nearby than those far away.

Andreasen responds to supporters of the trellis model by arguing that the population cluster results speak against the trellis model. As she puts it, "It is important to note that Templeton's objection applies only to phylogenetic trees constructed using genetic distance based methods. Since other methods of inferring population structure exist, his argument is somewhat limited in scope" $(2007,475)$. Andreasen then claims that clustering methods such as those used by Rosenberg et al. (2002) bypass the objection that Templeton raised. The assumption here seems to be that if programs like STRUCTURE are able to pick up on population structure, then this is evidence that there have been distinct lineages in the past. Or, as she puts it, the clustering can be "useful for identifying distinct lineages" (474). Since Andreasen also accepts that distinct lineages do not currently exist, she must be interpreting these population clusters as the residual effects of past distinct lineages.

slice. She does not mean by the phrase that the two populations have the dispositional characteristic such that they would reproduce at low rates were they to come into contact under normal circumstances (cf. Mayr 1942, 120), or that the two populations have developed phenotypic barriers to reproduction (cf. Coyne and Orr 2004).

15 . The claim that races are currently merely socially constructed does not necessarily conflict with the claim that race terms might still be biologically useful for certain purposes. For example, it could turn out that groups picked out by racial labels are statistically related to the residual clades from the past. 
Since Andreasen and Templeton are offering two distinct models of human evolutionary history, one ought to wonder whether the cluster results do in fact favor Andreasen's model over Templeton's. On the surface, it seems like they do. The fact that these studies found population clusters in the areas where biologists might expect to find distinct lineages in the past is a striking fact. The problem is that we would expect to find such clusters on Templeton's hypothesis as well. This problem arises because clustering programs like STRUCTURE are quick to find clusters when a population exhibits a pattern of isolation by distance. Recently, biologists have been testing whether the statistical clustering programs used in population genetics do in fact pick out the biologically important groups in the population. For example, Schwartz and McKelvey (2009) used computer simulations to assess the clusters that STRUCTURE picks out. They found that "for models where individuals (and their alleles) were randomly distributed across a landscape, STRUCTURE correctly predicted that only one population was being sampled. However, when gradients created by neighbor mating existed, STRUCTURE detected multiple, but different numbers of clusters, depending on sampling protocols" (441). Since Templeton's view is that neighbor mating is what accounts for the patterns in genetic variation we see in the human population, we should expect STRUCTURE to find clusters in the human population if Templeton is correct. And it would not be surprising that the clusters would correspond to the continental populations, since geographic barriers between those populations would likely cause gene flow to slow somewhat in exactly the right ways for those clusters to appear.

One might reply that, while this response defeats the claim that the clusters found by STRUCTURE are evidence in favor of Andreasen's account, there are newer programs that would likely find the same clusters. Safner et al. (2011) conducted a study showing that this kind of response fails to save an account like Andreasen's. They tested three of the successor programs, namely, BAPS5, TESS, and GENELAND, to see whether they exhibited the same problems as STRUCTURE. They found that "all methods incorrectly detected boundaries in the presence of strong patterns of isolation by distance" (866). This suggests that the pattern of isolation by distance that Templeton believes accounts for the clinal nature of human genetic variation is just the kind of pattern that is likely to be misinterpreted by these programs. Since we should expect the programs to pick out population clusters on either of these competing models of human evolutionary history, the clusters that have been found cannot serve as evidence in favor of one hypothesis over the other. Therefore, Andreasen was wrong to think that the cluster results could serve as evidence that cladistic subspecies once existed. Additionally, since the clusters in the data needed to be due to genetic isolation for Sesardic as well, we can conclude that the cluster data simply 
do not support the view that human races are biologically legitimate in the sense we are concerned with here.

5. Biological Data That Could Help Settle Whether Cladistic Races Once Existed. Since the statistical clustering programs are unable to help us determine whether races are biologically legitimate, one might wonder whether there are any currently available biological facts that could help. I claim that there are. Notice that Andreasen and Templeton are implicitly offering distinct accounts of why the human population exhibits clinal variation. For Andreasen, the reason we see a gradual variation in gene frequencies across the globe, and thus the reason the genetic distance data fail to exhibit treeness, is that the distinct lineages from the past have come back into contact and consequently started to reproduce along the edges. For Templeton, on the other hand, these clines have always been around. I believe that this difference is crucial to determining what kinds of biological facts could discern between the two models. Or, in other words, the differences in what caused the clines on each account would lead us to expect different kinds of variation in gene frequencies.

On Templeton's model, we would expect gene frequencies in intermediate populations to wander somewhat randomly away from the gene frequency values in the extreme populations. For example, human populations in the Middle East sit on a genetic cline between the populations of Africa and Asia. If we were to look at some randomly chosen polymorphic locus that we are pretty certain is selectively neutral, this model does not tell us whether the frequency in the Middle East will be between the frequencies we find in Africa and Asia. What causes genetic variation for selectively neutral genes on Templeton's model is simply the random walk of the genes due to the small effective population size that arises from neighbor mating. So, if we were to examine a number of selectively neutral genes in these three populations, we would expect to see the gene frequencies in the Middle East fall outside the frequency ranges in Africa and Asia rather often.

On Andreasen's account, on the other hand, we would not expect this kind of random walk at all. For her, the cline that we see between Africa and Asia was made when these two separated lineages came back into contact and began to exchange genes again. Thus, a population like the one in the Middle East is really an admixture between the two historically distinct populations. In cases like these, we would expect the vast majority of frequencies of selectively neutral genes in this intermediate population to fall between the frequencies in the extreme populations. This suggests that examining the gene frequencies in various intermediate populations around the world holds the key to determining whether the human population exhibited distinct lineages in the past. And since this factor is crucial to both Andreasen's cladistic race concept and Sesardic's populationist race con- 
cept, it should prove the most fruitful way to determine whether the population cluster results pick out, or at least approximate, biologically legitimate human races. This is work that remains to be done.

6. Conclusion. In this paper I have argued that although many scholars have attempted to use the recent population cluster results to revive the biological legitimacy of the human races, the data should not in fact shake our confidence that the human races are biologically suspect. First, the population clusters are entirely irrelevant to two of the predominant race concepts used in biology. Second, Sesardic's attempt to use the population clusters to support the existence of populationist races ultimately relies on the clusters being relatively distinct lineages. Third, I have shown that Andreasen's claim that the population clusters serve as evidence that the human population exhibited distinct lineages in the past is suspect-we should expect the clusters even if no distinct lineages ever existed. Last, I have sketched some biological facts that might help us determine whether the clusters do in fact correspond to biologically legitimate human races, thus suggesting a way forward in the biological race debate.

\section{REFERENCES}

Andreasen, Robin. 1998. "A New Perspective on the Race Debate." British Journal for the Philosophy of Science 49 (2): 199-225.

_ 2000. "Race: Biological Reality or Social Construct?" Philosophy of Science 67 (Proceedings): S653-S666.

—. 2004. "The Cladistic Race Concept: A Defense." Biology and Philosophy 19:425-42.

- 2005. "The Meaning of 'Race': Folk Conceptions and the New Biology of Race." Journal of Philosophy 102 (2): 94-106.

- 2007. "Biological Conceptions of Race." In Philosophy of Biology, ed. Dov Gabbay and Mohan Matthen, 455-81. Amsterdam: Elsevier.

Appiah, Kwame. 1996. "Why There Are No Human Races." In Conceptual Issues in Evolutionary Biology, ed. Elliott Sober, 455-75. Cambridge, MA: MIT Press.

Bamshad, Michael, Stephen Wooding, Scott Watkins, Christopher Ostler, Mark Batzer, and Lynn Jorde. 2003. "Human Population Genetic Structure and Inference of Group Membership." American Journal of Human Genetics 72:578-89.

Coyne, Jerry, and Allan Orr. 2004. Speciation. Sunderland, MA: Sinauer.

Dobzhansky, Theodosius. 1970. Genetics of the Evolutionary Process. New York: Columbia University Press.

Frantz, A. C., S. Cellina, A. Krier, L. Schley, and T. Burke. 2009. "Using Spatial Bayesian Methods to Determine the Genetic Structure of a Continuously Distributed Population: Clusters or Isolation by Distance?" Journal of Applied Ecology 46:493-505.

Gannett, Lisa. 2004. "The Biological Reification of Race." British Journal for the Philosophy of Science 55:323-45.

Glasgow, Joshua. 2009. A Theory of Race. New York: Routledge.

Hardimon, Michael. 2003. "The Ordinary Concept of Race." Journal of Philosophy 100:437-55.

_ 2012. "The Idea of a Scientific Concept of Race." Journal of Philosophical Research 37:249-82.

Kaplan, Jonathan. 2011. “'Race’: What Biology Can Tell Us about a Social Construct.” In Encyclopedia of Life Sciences. Chichester: Wiley. 
Kitcher, Philip. 1999. "Race, Ethnicity, Biology, Culture." Repr. in In Mendel's Mirror: Philosophical Reflections on Biology, 230-57. New York: Oxford University Press.

Lewontin, Richard. 1972. "The Apportionment of Human Diversity." Evolutionary Biology 6: 381-98.

Li, Jun, Devin Absher, Hua Tang, Audrey M. Southwick, Amanda Casto, Sohini Ramachandran, and Howard Cann. 2008. "Worldwide Human Relationships Inferred from Genome-Wide Patterns of Variation." Science 319:1100-1104.

Livingstone, Frank. 1962. "On the Non-existence of Human Races." Current Anthropology 3: $279-81$.

Long, Jeffrey, and Rick Kittles. 2003. "Human Genetic Diversity and the Nonexistence of Biological Races." Human Biology 75:449-71.

Mayr, Ernst. 1942. Systematics and the Origin of Species. New York: Columbia University Press.

Pigliucci, Massimo, and Jonathan Kaplan. 2003. "On the Concept of Biological Race and Its Applicability to Humans." Philosophy of Science 70:1161-72.

Pritchard, Jonathan, Matthew Stephens, and Peter Donnelly. 2000. "Inference of Population Structure Using Multilocus Genotype Data." Genetics 155:945-59.

Risch, Neil, Esteban Burchard, Elad Ziv, and Hua Tang. 2002. "Categorization of Humans in Biomedical Research: Genes, Race and Disease." Genome Biology 3:1-12.

Rosenberg, Noah, Jonathan Pritchard, James Weber, Howard Cann, Kenneth Kidd, Lev Zhivotovsky, and Marcus Feldman. 2002. "Genetic Structure of Human Populations." Science 298: 2381-85.

Safner, Toni, Mark Miller, Brad McRae, Marie-Josée Fortin, and Stéphanie Manel. 2011. "Comparison of Bayesian Clustering and Edge Detection Methods for Inferring Boundaries in Landscape Genetics." International Journal of Molecular Sciences 12:865-89.

Schwartz, Michael, and Kevin McKelvey. 2009. "Why Sampling Scheme Matters: The Effect of Sampling Scheme on Landscape Genetic Results." Conservation Genetics 10:441-52.

Sesardic, Neven. 2010. "Race: A Social Destruction of a Biological Concept." Biology and Philosophy 25:143-62.

Sober, Elliott. 1980. "Evolution, Population Thinking, and Essentialism." Philosophy of Science 47:350-83.

Spencer, Quayshawn. 2012. "What 'Biological Racial Realism' Should Mean.” Philosophical Studies 159:181-204.

_ 2013. "Biological Theory and the Metaphysics of Race: A Reply to Kaplan and Winther." Biological Theory 8:114-20.

Templeton, Alan. 1998. "Human Races: A Genetic and Evolutionary Perspective." American Anthropologist 100:632-50.

Wilson, Robert, Matthew Barker, and Ingo Brigandt. 2007. "When Traditional Essentialism Fails: Biological Natural Kinds.” Philosophical Topics 35:189-215.

Winther, Rasmus, and Jonathan Kaplan. 2013. "Ontologies and Politics of Bio-genomic 'Race.'” Theoria 60:54-80. 